\title{
THE FREQUENCY OF ENTRY INTO AN ETHMOIDAL SINUS WHEN PERFORMING A DACRYOCYSTORHINOSTOMY
}

\author{
S. J. TALKS and B. HOPKISSON \\ Northampton
}

\begin{abstract}
SUMMARY
Ethmoidal sinuses intervening between the lacrimal sac and the nose can cause confusion when performing a dacryocystorhinostomy (DCR). This study aimed to assess the frequency of entry into ethmoidal sinuses when performing a DCR and to identify any helpful distinguishing features, at surgery, between the ethmoidal and nasal spaces. Ethmoidal sinuses were initially entered in 23 of 50 standard DCRs $(46 \%)$ in which the ostium was formed via the lacrimal fissure. Nasal mucosa was found to be 2 to 3 times thicker than ethmoidal sinus mucosa and less friable. Being aware of the risk of entering an ethmoidal sinus and of the anatomical differences between ethmoidal and nasal tissue greatly aids location during surgery and allows edge-to-edge suturing of sac mucosa to nasal mucosa in all cases.
\end{abstract}

For a successful dacryocystorhinostomy (DCR) it is important to make an adequate ostium into the nose. Indeed it is recommended that all bone between the lacrimal sac and the nasal mucosa be removed, such that no bone is left within $5 \mathrm{~mm}$ of the common canaliculus. Thus following DCR, the sac and duct should no longer exist as separate anatomical structures but instead be incorporated into the nose. ${ }^{1}$ For this to be achieved the surgeon has to be able to identify his or her exact anatomical location at all steps of the operation. One cause for failure of a DCR is making an opening into an ethmoidal sinus rather than the nose and anastomosing the lacrimal sac to ethmoidal sinus mucosa. ${ }^{1,2}$ In this study we observed how frequently, when making the ostium, an ethmoidal sinus was initially entered using a standard DCR technique. ${ }^{3}$ We also compared nasal and ethmoidal mucosa and found that the

From: Northampton General Hospital, Billing Road, Northampton NN1 5BD, UK

Correspondence to: Mr S. J. Talks, MRCP, FRCOphth, The Eye Hospital, The Radcliffe Infirmary, Woodstock Road, Oxford OX2 6HE, UK. difference easily enables a surgeon to identify his or her anatomical location. This information should help prevent the inadvertent suturing of sac mucosa to ethmoidal mucosa.

\section{METHODS}

We carried out 50 consecutive, primary DCRs in adults. The initial cavity entered, either ethmoidal sinus or nose, was documented, as was the nature of the mucosa lining the cavity. The nose was not packed prior to surgery but a cotton bud soaked in $4 \%$ cocaine was inserted up the nose to underlie the potential ostium. The rhinostomy was commenced by splitting, with a Traquair's periosteal elevator, the suture between the lacrimal bone and the frontal process of the maxilla in the medial wall of the lacrimal fossa. The underlying mucosa was carefully separated from the bone to be removed, using the elevator, and the ostium enlarged with a bone punch. If no anterior ethmoidal sinus intervened, the underlying muco-periostium (nasal mucosa) could be indented with a curved artery forcep passed up the nose. If the initial cavity entered was in fact an ethmoidal sinus a blind cul de sac was encountered anteriorly as bone was removed and a curved artery forcep up the nose did not indent the medial wall of the sinus. Ragged, thin friable mucosa was identified lining the space, often with thin eggshell-like bone intervening between the ragged mucosa and the thick nasal mucosa medially. Once the thin ethmoidal mucosa and eggshell bone had been removed, the artery forcep up the nose could again visibly indent the nasal mucosa.

For illustrative purposes we biopsied the mucosa in six representative cases.

\section{RESULTS}

An ethmoidal sinus was entered initially in 23 of the 50 consecutive adult cases (46\%). Macroscopically the ethmoidal mucosa was seen to be much thinner and more friable than nasal mucosa, in every case. 


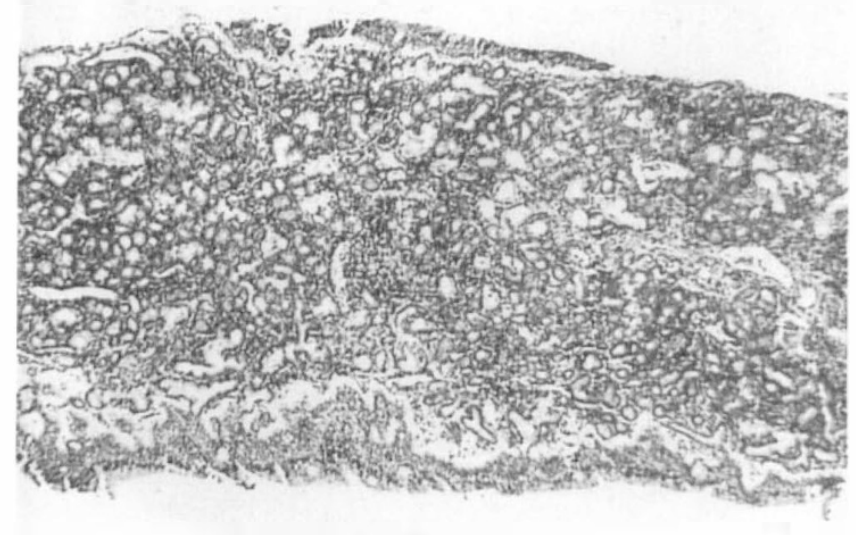

(a)

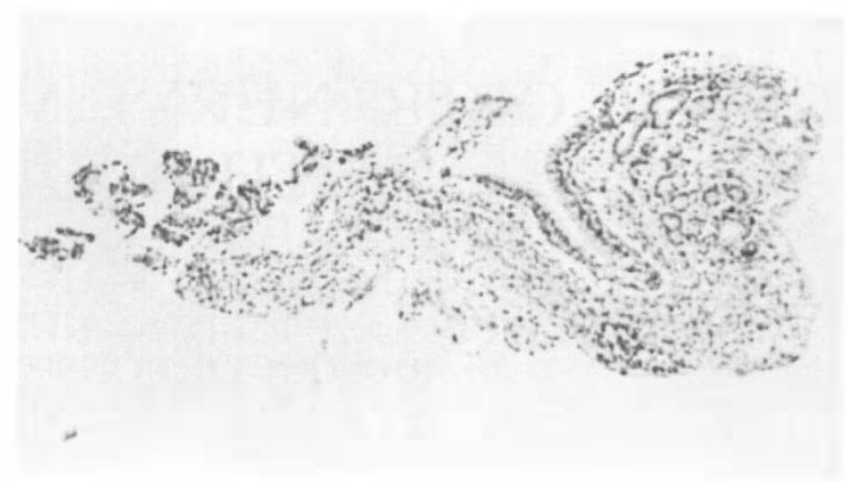

(b)

Fig. 1. (a) Nasal mucosa; (b) ethmoidal mucosa (H\&E stain, $\times 25)$. The main reason for the difference in thickness of nasal mucosa compared with ethmoidal mucosa is the larger amount of submucosal glandular tissue evident in nasal mucosa.

Microscopically it could be seen that nasal mucosa is 2 to 3 times thicker than ethmoidal mucosa. This was true for each of the six cases. The mean ethmoidal thickness was $0.62 \mathrm{~mm}$ (range $0.28-0.75 \mathrm{~mm})$. The mean nasal mucosal thickness was $1.5 \mathrm{~mm}$ (range $1.32-1.75 \mathrm{~mm}$ ) (Fig. 1).

\section{DISCUSSION}

We have found that it is common to enter ethmoidal sinuses when performing a standard DCR via the suture in the medial wall of the lacrimal fossa. Ethmoidal sinuses are known to be variable in their size, number and position, varying from three large sinuses on each side to 18 small ones. ${ }^{4}$ The close relationship of the ethmoidal sinuses to the lacrimal sac fossa has long been recognised. ${ }^{5-7}$ A CT scan study of ethmoidal anatomy found that in $41 \%$ of cases the sinuses extended anteriorly to the lacrimal bone suture. ${ }^{8}$ Our results surgically confirm this finding. However, the positioning of the ostium clearly influences the likelihood of entering an ethmoidal sinus. Pico, ${ }^{9}$ using a $10 \mathrm{~mm}$ Iliff trephine on a Stryker saw placed on the anterior lacrimal crest, initially entered an ethmoidal sinus in only 3 of 121 cases, as his entry point was more anterior than ours. The frequency with which ethmoidal sinuses are entered using the lacrimal suture as the initial entry point does not seem to be well recognised and is a trap for the unwary. It is important to recognise that an inappropriate anastomosis of lacrimal sac mucosa to ethmoidal mucosa may be formed and that the ostium will not be opened into the nasal cavity, or not adequately so.

Anatomically paranasal sinus mucosa is continuous with that of the nasal cavity and is similar histologically, although thinner, less vascular and less adherent to bone. ${ }^{4}$ The main reason for the difference in thickness is that nasal mucosa has more glandular tissue. The extra thickness and strength of nasal mucosa compared with ethmoidal sinus mucosa is especially helpful clinically in distinguishing between the two types. This feature can be very useful to the surgeon for confirming his or her anatomical location, and thus prevent an inappropriate anastomosis.

CT scanning has been advocated prior to DCR, especially with endonasal approaches, to help to clarify the presence of intervening ethmoids. ${ }^{10} \mathrm{We}$ believe that with adequate knowledge of the anatomy and, in particular, the marked distinction between ethmoidal and nasal mucosa, the use of expensive CT scanning is unnecessary. The success rate of our DCRs is over $90 \%$.

Key words: Dacryocystorhinostomy, Ethmoid, Mucosa.

\section{REFERENCES}

1. Welham RAN, Wulc AE. Management of unsuccessful lacrimal surgery. Br J Ophthalmol 1987;71:152-7.

2. Glatt HJ, Chan AC, Barrett L. Evaluation of dacryocystorhinostomy failure with computed tomography and computed tomographic dacryocystography. Am J Ophthalmol 1991;112:431-6.

3. Roper Hall M. Stallard's eye surgery, 7th ed. Bristol: Wright, 1989:149-56.

4. Bannister L. Respiratory system. In: Williams PL, chief editor. Gray's anatomy, 38th ed. Edinburgh: Churchill Livingstone 1995:1635-6.

5. Mosher HP. The surgical anatomy of the ethmoid labyrinth. Ann Otol Rhinol Laryngol 1929;38:869-901.

6. Whitnall SE. The relations of the lacrimal fossa to the ethmoid cells. Ophthalmic Rev 1911;30:321-5.

7. Mattox DE, Delaney RG. Anatomy of the ethmoid sinus. Otolaryngol Clin North Am 1985;18:3-42.

8. Blaylock WK, Moore CA, Linberg JV. Anterior ethmoid anatomy facilitates dacryocystorhinostomy. Arch Ophthalmol 1990;108:1774-7.

9. Pico G. A modified dacryocystorhinostomy. Am J Ophthalmol 1971;72:679-90.

10. Whittet HB, Shun-Shin GA, Awdry P. Functional endoscopic transnasal dacryocystorhinostomy. Eye 1993; 7:545-9. 